\title{
Protective effect of luteolin against oxidative stress during hypoxic ischemia-induced neuronal damage in neonatal rats
}

\author{
Weihong Cao, Jun Luo, Jingwei Peng, Xiaoxia Zhu, Shigang Li, Jilong Ma* \\ Department of Paediatrics, Affiliated Renhe Hospital of China Three Gorges University, Yichang, Hubei, China
}

*For correspondence: Email: jilongma1986@hotmail.com; Tel/Fax: 0086-0717-6554671

Sent for review: 17 October 2020

Revised accepted: 21 March 2021

\begin{abstract}
Purpose: To investigate the neuroprotective efficacy of plant polyphenol luteolin against hypoxic ischemia (HI)-induced neuronal injury in neonatal rat pups.

Methods: Postnatal rat pups (aged 7 days) were subjected to $\mathrm{HI}$ insult, and then treated with luteolin at a dose of $1.2 \mathrm{mg} / \mathrm{kg}$ body weight (bwt) for up to 4 days after HI injury. Following the sacrifice of the pups, the brain tissues were subjected to histological examination ( $H \& E$ staining), as well as biochemical and antioxidant assays. Moreover, levels of cell death regulator proteins were determined by enzyme-linked immunosorbent assay (ELISA).

Results: There was significant increase in the tissue levels of reactive oxygen species (ROS) and malondialdehyde (MDA), but marked decrease in mitochondrial membrane potential $\left(\triangle \Psi_{m}\right)$ in the $H I$ rat pups $(p<0.05)$. Furthermore, $H I$ decreased the brain tissue levels of the antioxidants, SOD, CAT, GPX and $\mathrm{GSH}$, in the postnatal pups. However, luteolin treatment significantly reversed the abnormal increase in the levels of ROS and MDA, but reduced the loss in mitochondrial membrane potential $\left(\Delta \Psi_{m}\right)$, while increasing the levels of SOD, CAT GPX and GSH $(p<0.05)$. Furthermore, HI significantly increased the brain expression levels of the pro-apoptotic markers, i.e., cytosolic cytochrome $C$ (cyt c), caspase- 3 and caspase- 9 in the pups exposed to HI, indicating neuronal cell death. However, the HIinduced increase in the expression levels of these pro-apoptotic factors was reduced by luteolin treatment.

Conclusion: These results suggest that luteolin protects postnatal rat pups from hypoxic ischemicinduced brain damage (neuronal cell death) due to its antioxidant and free radical-scavenging activities. Therefore, luteolin may be a potential neuroprotective agent in the management of HI-associated complications.
\end{abstract}

Keywords: Antioxidants, Hypoxia, Ischemia, Luteolin, Neuronal cell death, Neuroprotection

\begin{abstract}
This is an Open Access article that uses a fund-ing model which does not charge readers or their institutions for access and distributed under the terms of the Creative Commons Attribution License (http://creativecommons.org/licenses/by/4.0) and the Budapest Open Access Initiative (http://www.budapestopenaccessinitiative.org/read), which permit unrestricted use, distribution, and reproduction in any medium, provided the original work is properly credited.

Tropical Journal of Pharmaceutical Research is indexed by Science Citation Index (SciSearch), Scopus, International Pharmaceutical Abstract, Chemical Abstracts, Embase, Index Copernicus, EBSCO, African Index Medicus, JournalSeek, Journal Citation Reports/Science Edition, Directory of Open Access Journals (DOAJ), African Journal Online, Bioline International, Open-J-Gate and Pharmacy Abstracts
\end{abstract}

\section{INTRODUCTION}

Perinatal hypoxic ischemic $(\mathrm{HI})$ encephalopathy which is characterized by cognitive, retarded growth, motor and sensory problems, is a principal cause of disability in infants [1]. At present, about $25 \%$ of infant mortality in the world is recorded during intrapartum asphyxia 
due to HI-induced neuronal damage. Studies have shown that several events contribute to neuronal damage during perinatal $\mathrm{HI}$. These factors include loss of ATP, excitotoxicity, failure of calcium export or import, and generation of free radicals. Neonatal brain is rich in fatty acids, and it consumes high levels of oxygen $\left(\mathrm{O}_{2}\right)$. Thus, a defective antioxidant system (low expressions of SOD and GPX) makes it prone to free radical and lipid peroxidation insults [2,3]. Moreover, increased iron $\left(\mathrm{Fe}^{2+}\right)$ levels in neonatal brain enhance ROS generation via the Fenton reaction and generation of hydroxyl radical $(\mathrm{OH})$ in normal cells, making them rapidly more prone to brain damage. The ROS disrupt the mitochondrial membrane and enhance the release of cytochrome $c$ into the cytosol, leading to increased expressions of apoptotic proteins Bax, Bid, and Bam, while downregulating Bcl-2 (an anti-apoptotic protein), leading to neuronal apoptosis [4]. Although various treatment measures such as stem cell therapy [9], mitochondrial therapy and magnesium therapy have been developed for the management of $\mathrm{HI}$ encephalopathy, none of them has shown a promising potential [5]. In contrast, studies have shown that plant- and marine-based compounds with significant antioxidant potential reduce neonatal $\mathrm{HI}$-induced brain injury $[6,7]$. In this study, the effect of the plant-derived phenolic compound luteolin on neonatal $\mathrm{HI}$ insult was investigated. Luteolin is well known for its protective ability against oxidative stress induced inflammation, and for its anticancer and neurotrophic properties $[8,9]$.

\section{EXPERIMENTAL}

\section{Animals}

Pathogen-free of sixty-day-old pregnant Sprague-Dawley rats weighing 200 to $250 \mathrm{~g}$ were procured from Animal Experimental Center of Ningxia Medical University, Yinchuan, China (permit no. SCXK Ningxia 2015-0001). Experiments involving neonatal rats were approved by the institutional animal ethical committee of China Three Gorges University, Yihchang, Hubei, China (approval no. 2018-MA105). Animals were treated in accordance with Guide for the Care and Use of Laboratory Animals (8th edition, National Academies Press) [10]. All rats were housed in individual cages under constant 12-h light/12-h dark cycle at controlled temperature $\left(21^{\circ} \mathrm{C}\right)$. The animals were housed in clean polypropylene cages, and were provided access to water and feed ad libitum. Male neonatal pups were taken from the litter of the pregnant rats, with the day of litter designated day 0 (P0). Pups from day 7 were chosen for experimental purpose, since it has been reported that they are comparable to human neonates aged 32 to 34 weeks [11]. The neonatal rats were randomly picked and divided into four experimental groups, with 6 pups per group. Group I was sham control, while group II comprised $\mathrm{HI}$ pups given saline (vehicle control). Group III were HI pups administered oral luteolin up to the end of the experiment. Group IV pups were positive control animals which received only luteolin, without $\mathrm{HI}$ insult. Luteolin was dissolved in saline and orally administered as single dose of $1.2 \mathrm{mg} / \mathrm{kg}$ bwt. This dose was optimized based on effective dose studies.

Hypoxic Ischemia $(\mathrm{HI})$ was induced via inhalation of air containing $8 \%$ oxygen and $92 \%$ nitrogen, in line with previous studies [12]. Seven-day-old pups (P7) were anaesthetized with 2-3\% isoflurane via inhalation. The carotid artery (CCA) at the right ventricle was surgically exposed, double-ligated using 5.0 silk surgical sutures, and then cut open between two the ligation sites. After surgery, the pups were allowed to recuperate for $1.5 \mathrm{~h}$ and placed in a hypoxic incubator (containing $8 \%$ oxygen and 92 $\%$ nitrogen) for $1.5 \mathrm{~h}$ at $37{ }^{\circ} \mathrm{C}$. Inhalation of $8 \%$ oxygen-adjusted nitrogen is used widely to induce $\mathrm{HI}$ in rat pups. This protocol was followed from previous studies, but with slight modifications [12]. The animals were allowed to recover after the hypoxic treatment. In the sham group, CCA was exposed but without ligation and hypoxic treatment.

Luteolin was obtained from Selleck (Shanghai, China) and dissolved in $0.1 \%$ sterile physiological saline to obtain the desired concentration, prior to administer to rat pups.

Luteolin was administered every $12 \mathrm{~h}$ for 4 consecutive days after induction of $\mathrm{HI}$ injury. The sham and $\mathrm{HI}$ pups were treated with saline (vehicle control). At the end of the experiment, the animals were sacrificed using intraperitoneal injection of chloral hydrate. Portions of the brain tissue were immediately fixed in $4 \%$ formaldehyde for use in histological analysis, while the remaining brain tissue samples were stored in $-80^{\circ} \mathrm{C}$ for further studies.

\section{Measurement of ROS}

Levels of ROS in brain tissue homogenate were quantified using 2'-7'-dichlorofluoresceindiacetate (DCFH-DA) assay, based on the oxidation of $\mathrm{DCFH}$ to the fluorescent form 2', 7 'dichlorofluorescein (DCF) [13]. The formation of DCF was measured spectrofluorimetrically at 
excitation and emission wavelengths of 504 and $529 \mathrm{~nm}$, respectively.

\section{Measurement of lipid peroxidation}

The lipid peroxidation product malondialdehyde (MDA) was estimated using the method described in a previous report [14]. In this method, $200 \mu \mathrm{L}$ supernatant from brain tissue homogenate was added to $50 \mu \mathrm{L}$ of $8.1 \%$ sodium dodecyl sulfate in a vial, and the vial was vortexed for few seconds. Thereafter, the mixture was incubated at room temperature for $10 \mathrm{~min}$, followed by addition of $1.25 \mathrm{ml}$ of butanol: pyridine mixture. After vortexing for a few seconds, the vial was centrifuged at $1000 \mathrm{rpm}$ for $5 \mathrm{~min}$, and the OD was read at $532 \mathrm{~nm}$ in a spectrophotometer. The OD reading was used to calculate the concentrations of MDA formed.

\section{Assay of mitochondrial membrane potential} $(\Delta \Psi \mathrm{m})$

Mitochondrial membrane potential (transmembrane potential, $\Delta \Psi_{\mathrm{m}}$,) of brain tissue cells was measured using safranin, a fluorescent probe, according to the method described previously [15]. The spectrofluorimetric experimental values were recorded at excitation and emission wavelengths of 520 and $580 \mathrm{~nm}$, respectively.

\section{Assay of antioxidants}

The activities of SOD, CAT and GPx, and concentration of GSH in brain tissue were determined using commercially determined using assay kits obtained from Nanjing Jiancheng Bioengineering Institute (Nanjing, China). All the antioxidant analyses were performed within $48 \mathrm{~h}$ of sample collection.

\section{Assay of nitric oxide}

Total nitric oxide (NO) concentration in brain tissue sample was estimated spectrophotometrically using the Griess reagent. The concentration of nitrate by-products in brain tissue homogenates was measured using total nitric oxide assay kit from Beyotime, Jiangsu, China).

\section{Determination of cytosolic cytochrome C}

Levels of cytosolic cytochrome C were determined with cytochrome $c$ ELISA kit (BioVision, Inc., USA). A portion of brain tissue was lysed at $4^{\circ} \mathrm{C}$ for $10 \mathrm{~min}$ in cold lysis buffer comprising at $\mathrm{pH}$ 7.5. Cytosolic supernatants from tissue homogenates were centrifuged at
$10,000 \mathrm{~g}$ at $4{ }^{\circ} \mathrm{C}$ for $60 \mathrm{~min}$. The supernatant (cytosolic fraction) was used for protein quantification with bicinchoninic acid (BCA) assay kits as per manufacturer's instructions. At the end of reaction, the OD was read at $450 \mathrm{~nm}$ using a microplate reader.

\section{Assay of protein expressions of apoptotic markers}

The expression levels of caspase- 3 and caspase- 9 were assayed using a commercial caspase activity assay kit (BioVision Inc., USA). A portion of brain tissue was homogenized, and the amount of protein in the homogenate was quantified with protein estimation kit (BioVision Inc) as per manufacturer's instructions. Then, protein aliquots from the sham and experimental groups $(20-50 \mu \mathrm{g})$ were treated as per manufacture's instruction (BioVision Inc., USA). The absorbance values of the assay end-product (phospho-nitroanilide) for caspase-3 and caspase- 9 were measured at 405 and $505 \mathrm{~nm}$, respectively, using a spectrophotometer.

\section{Hematoxylin and eosin staining}

A portion of brain tissue from each experimental group of pups was incubated with paraformaldehyde at $4^{\circ} \mathrm{C}$ and dehydrated with graded concentrations of ethanol. The dehydrated brain tissue was embedded in paraffin wax. Then, $5-\mu \mathrm{m}$ thick coronal sections of brain tissue were cut using a microtome, and the sections were stained with hematoxylin and $\operatorname{eosin}(H \& E)[6]$.

\section{Statistical analysis}

Results are expressed as mean \pm standard deviation (SD). Data analysis was performed using SPSS 14.0 software (SPSS Inc., Chicago, IL, USA). Triplicate values of all the experimental results were subjected to one-way analysis of variance (ANOVA), followed by least significant difference (LSD) test. Statistical significance was assumed at $p<0.05)$.

\section{RESULTS}

\section{Luteolin reduced ROS and oxidative stress}

Total brain tissue homogenates from $\mathrm{HI}$ induced hemisphere were used for ROS estimation. Brain tissue samples from $\mathrm{Hl}$-induced pups showed significant increases in the levels of ROS and MDA $(p<0.05)$, while treatment with luteolin significantly reduced the abnormal increases in ROS in $\mathrm{HI}$ group brain tissue samples $(p<0.05)$. In contrast, the drug control and sham control 
rats exhibited normal levels of ROS and MDA. These results are presented in Figure 1.

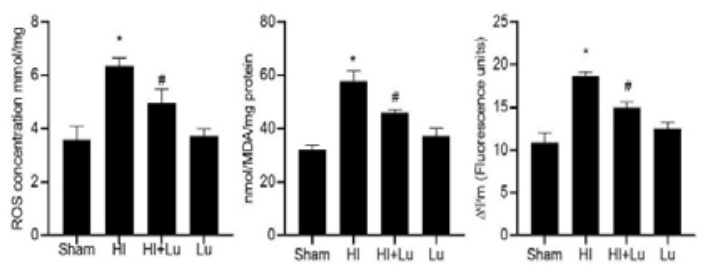

Figure 1: Total ROS and MDA level, and mitochondrial membrane potential $\left(\Delta \Psi_{\mathrm{m}}\right)$ of cells in brain tissues of various experimental groups of neonatal pups. Results are expressed as mean $\pm \mathrm{SD}$. ${ }^{*} P<0.05$ (HI group compared to control); $\# p<0.05$ (luteolin-treated group compared to $\mathrm{HI}$ ); NS (luteolin group without $\mathrm{HI}$ compared with sham control). ROS levels are expressed as $\mathrm{mmol} / \mathrm{mg}$, while MDA levels are expressed as nmoles/MDA/mg protein

\section{Luteolin reduced loss of mitochondrial membrane potential $(\Delta \Psi \mathrm{m})$}

Brain tissue homogenates from all the experimental groups were used for measurement of mitochondrial membrane potential. Figure 1 shows that $\mathrm{HI}$ significantly decreased $\Delta \Psi_{\mathrm{m}}$ in rat pup brain tissues $(p<0.05)$. However, luteolin treatment markedly reversed the HI-induced decreases in $\Delta \Psi_{\mathrm{m}}(p<0.05)$. The drug control and sham control rats did not show any significant changes in $\Delta \Psi \mathrm{m}$.

\section{Luteolin restored antioxidant levels}

Levels of antioxidant enzymes were measured in brain tissue homogenates of all the experimental groups (Figure 2). Pups that received $\mathrm{HI}$ insult had significantly reduced levels of SOD, CAT, GPX and GSH $(p<0.05)$, while treatment with luteolin significantly restored the levels of these parameters close to normalcy $(p<0.05)$. There were no significant changes in levels of SOD, CAT, GPX and GSH in the drug control and sham control neonatal rat pups.

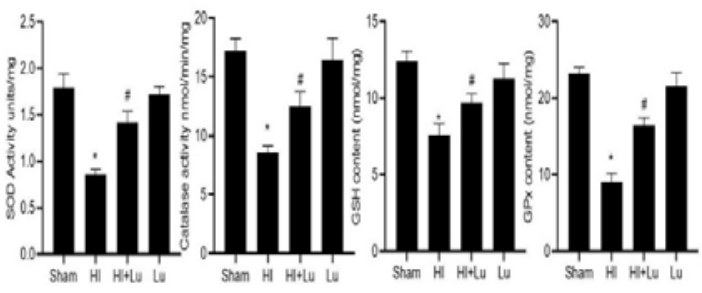

Figure 2: Antioxidant profiles (SOD, CAT, GSH and GPx) in brain tissue hypoxic ischemic hemispheres. Results are expressed as mean $\pm \mathrm{SD} .{ }^{*} P<0.05(\mathrm{HI}$ compared to control); \#p $<0.05$ (luteolin-treated group compared to $\mathrm{HI}$ ); NS (luteolin-alone group compared with control). SOD levels are expressed as units/mg;
CAT levels are expressed as $\mathrm{nmol} / \mathrm{min} / \mathrm{mg}$, while GPX and GSH levels are expressed as $\mathrm{nmol} / \mathrm{m}$

\section{Luteolin reduced levels of nitric oxide}

The status of nitric oxide, a gaseous intracellular free radical which functions as an ubiquitous neuromodulator was determined in rat pup brain tissues of control and experimental groups. Figure 3 shows that $\mathrm{HI}$ significantly increased the levels of $\mathrm{NO}$ in rat pup brain tissues $(p<0.05)$. However, these increases in NO levels were markedly reduced by luteolin. The drug control and sham control rats maintained basal levels of $\mathrm{NO}$ generation in brain tissues of rat pups.

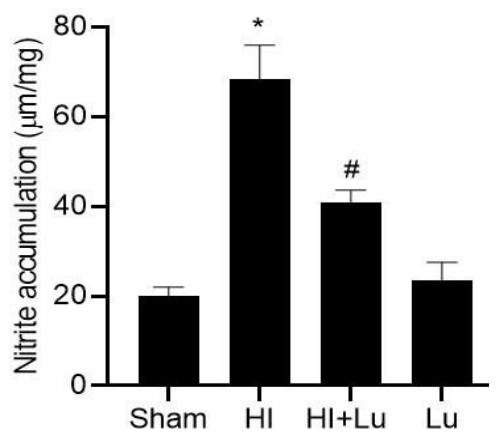

Figure 3: Status of nitric oxide accumulation as nitrite generation in brain tissues of hypoxic ischemic hemispheres. Results are expressed as mean \pm SD. ${ }^{*} P<0.05$ (HI group compared to control); $\# p<0.05$ (luteolin-treated group compared to HI); NS (luteolinalone group compared with control). Nitrite levels are expressed as $\mu \mathrm{m} / \mathrm{mg}$

\section{Hypoxic ischemia-induced brain lesion was normalized by luteolin}

The protective the effect of luteolin against HIinduced brain damage was assessed histologically using $\mathrm{H}$ \& $\mathrm{E}$ staining of brain tissue. Sham group brain tissue sections showed normal, intact and round-shaped cell bodies, while tissue sections from the $\mathrm{HI}$ group showed atrophic cell bodies. In contrast, tissue sections from rat pups given luteolin treatment after $\mathrm{HI}$ insult manifested reduced cell atrophy and nearnormal morphology (Figure 4). The brain tissue of animals treated with luteolin presented normal cellular morphology, indicating that luteolin did not produce any toxic effects.

\section{Luteolin inhibited apoptosis}

In order to determine the inhibitory effect of luteolin on cell death after $\mathrm{HI}$ in rat pup brain tissues, the levels of cytosolic cyto $C$, and expression levels of caspase- 3 and caspase- 9 were assayed. 
A

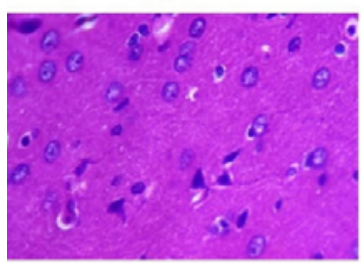

C
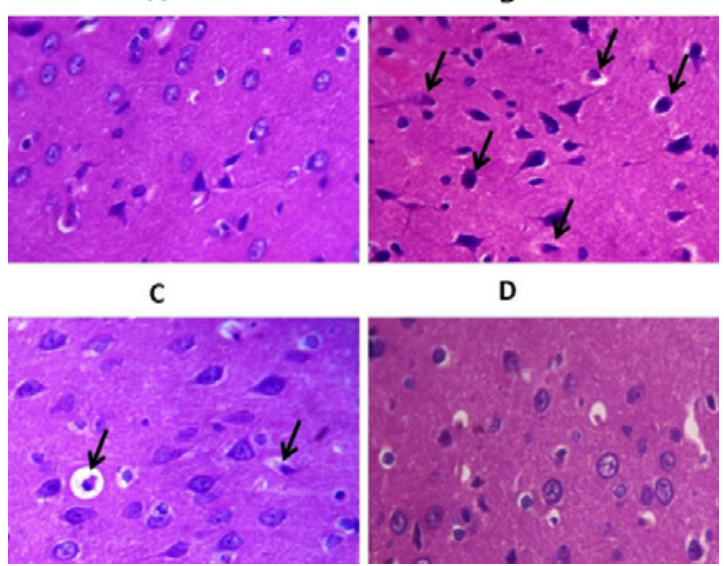

D

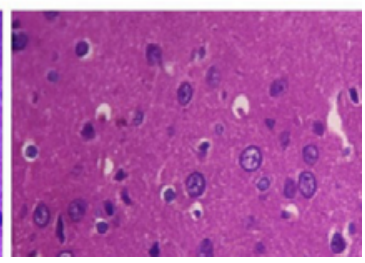

Figure 4: Photomicrographs of neonatal pup brain tissues. A: Control group showing normal, intact and round shaped cell bodies. B: Cells with atrophic cell bodies showing intense staining. C: Treated cells revealing reduced cell atrophy and near normal morphology. D: Drug control showing normal cellular morphology

As shown in Figure 5, cyto c level was significantly increased in brain tissues of rat pups subjected to $\mathrm{HI}(p<0.05)$. However, treatment with luteolin led to significant reduction of cytoplasmic cyto $c$ levels in brain tissues of rat pups with $\mathrm{HI}(p<0.05)$. Similar patterns were observed in expression levels of caspase-3 and caspase-9 in $\mathrm{HI}$ and luteolin-treated groups. The drug control and sham control rat pup brain tissues exhibited normalcy in the levels of cytoc $c$ and expression levels of caspase- 3 and caspase9.

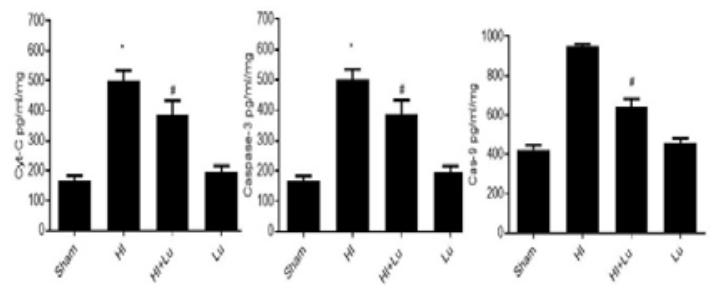

Figure 5: Expression patterns of apoptotic proteins (cyt c, caspase-3 and caspase-9) in brain tissues of $\mathrm{HI}$ hemispheres. Results are expressed as mean $\pm \mathrm{SD}$. ${ }^{*} P<0.05(\mathrm{HI}$ group compared to control); \#p $<0.05$ (luteolin-treated group compared to $\mathrm{HI}$ group); NS (luteolin-alone group compared with control)

\section{DISCUSSION}

For several decades, pharmacological studies have attempted to identify antioxidants with potential neuroprotective effects. Given the fact that neurological disabilities are caused by various endogenous and exogenous factors, there is a medical need for neuroprotective agents. This study has demonstrated the neuroprotective potential of luteolin against $\mathrm{HI}$ induced neonatal brain injury in vivo. Posttreatment with luteolin markedly reduced oxidative stress markers, restored mitochondrial membrane potential, and inhibited apoptosis, thereby exerting neuroprotection. Luteolin, a plant-derived polyphenol, has been found to possess beneficial effects such as antioxidant [14], anti-cancer [16], anti-inflammatory [17], and neurotrophic properties [18]. Studies have suggested that ROS generation and the concomitant oxidative stress are the major pathological mediators of neuronal injury during HI [19]. Abnormalities in antioxidant defence are the most significant factors that cause severe $\mathrm{HI}$ consequences in normal brain tissue, along with high oxygen consumption and increased metabolic rate [20].

In this study, $\mathrm{HI}$ rat pups showed increased ROS and MDA levels in brain tissue sections. These depict increased oxidative stress and neuronal injury in rat pups subjected to HI. However, treatment with luteolin significantly reversed the $\mathrm{HI}$-induced increases in ROS and MDA in brain tissues. These data suggest that luteolin exerted potent and significant antioxidative effect on neuronal injury during neonatal stage of $\mathrm{HI}$ insult. These results are in agreement with previous findings on the protective effect of resveratrol against experimental $\mathrm{HI}$-induced brain injury [21]. Cells in the nervous system are endowed with protective mechanisms such enzymic and nonenzymic antioxidant defences (SOD, CAT, GPX and $\mathrm{GSH}$ ) which scavenge free radicals [22]. In this study, these endogenous antioxidant defences might have been overwhelmed by the supraphysiologic levels of ROS generated by $\mathrm{HI}$. Luteolin treatment significantly restored the levels of SOD, CAT, GPX, and GSH, thereby demonstrating the protective potential of luteolin against $\mathrm{HI}$-induced oxidative injury. It has been reported that luteolin acts as an antioxidant via self-oxidation. This might have helped in quenching the excess ROS generated during $\mathrm{HI}$ brain injury. Photomicrographs from $H$ \& $E$ staining of pup brain tissue also showed less damage in luteolin-treated group than in $\mathrm{HI}$ group. The results of the present study clearly indicate that the antioxidant potential of luteolin may attenuate traumatic brain injury [23].

It has been reported that during cerebral ischemia, NO exerted potential cerebral brain injury via oxidative damage to the mitochondrial respiratory chain, leading to ATP depletion [24]. In the present study, the level of $\mathrm{NO}$ was markedly increased in $\mathrm{HI}$ rat pups, in addition to reduced/altered mitochondrial membrane 
potential. However, luteolin reduced the levels of $\mathrm{NO}$ and restored the mitochondrial membrane potential. It is well known that loss of mitochondrial membrane potential leads to release of cytochrome $\mathrm{c}$ into cytosol, thereby activating the apoptotic cascade [15]. In the present study, the levels of cytc c, caspase- 3 and caspase- 9 were markedly increased, signifying neuronal cell death. Brain tissue architecture appeared normal in pups that received luteolin treatment following $\mathrm{HI}$ insult. However, the $\mathrm{HI}$ induced atrophic cell body and apoptosismediated neuronal cell death were effectively reversed in pups treated with luteolin. These abnormalities were not observed in brain tissues of sham and luteolin-treated pups. Luteolin reversed the abnormal increases in levels of cyto c, caspase-3 and caspase-9, thereby protecting the brain against HI-induced neuronal cell death. The results of this study are in good agreement with previous pharmacological studies on plantderived compounds, especially with respect to regulation of apoptosis during $\mathrm{HI}$ neuronal injury.

\section{CONCLUSION}

The results of this study indicate that luteolin protects brain tissues of $\mathrm{HI}$ rat pups from apoptosis-induced neuronal cell death, and restores the mitochondrial membrane potential of the cells through scavenging of free radicals due to its antioxidant property. Thus, luteolin may be useful as neuroprotective agent in the management of neonatal hypoxic ischemic conditions.

\section{DECLARATIONS}

\section{Acknowledgement}

The authors appreciate the help from the central laboratory of Affiliated Renhe Hospital of China Three Gorges University, Yichang, Hubei

\section{Conflict of interest}

No conflict of interest is associated with this work.

\section{Contribution of authors}

This study was done by the author(s) named in this article and all liabilities pertaining to claims relating to the content of this article will be borne by the authors. The study was conceived and designed by Weihong Cao, Jun Luo, Jingwei Peng, and Jilong Ma. Xiaoxia Zhu and Shigang Li collected and analyzed the data Weihong Cao and Jilong Ma wrote the manuscript. All authors read and approved the manuscript of the present form for publication.

\section{Open Access}

This is an Open Access article that uses a funding model which does not charge readers or their institutions for access and distributed under the terms of the Creative Commons Attribution License (http://creativecommons.org/licenses/by/ 4.0) and the Budapest Open Access Initiative (http://www.budapestopenaccessinitiative.org/rea d), which permit unrestricted use, distribution, and reproduction in any medium, provided the original work is properly credited.

\section{REFERENCES}

1. Qin X, Cheng J, Zhong $Y$, Mahgoub OK, Akter F, Fan $Y$, Aldughaim M, Xie Q, Qin L, Gu L, et al. Mechanism and Treatment Related to Oxidative Stress in Neonatal Hypoxic-Ischemic Encephalopathy. Front Mol Neurosci 2019; 12: 88.

2. Aridas JD, Yawno $T$, Sutherland $A E$, Nitsos I, Ditchfield $M$, Wong FY, Fahey MC, Malhotra A, Wallace EM, Jenkin $G$, et al. Detecting brain injury in neonatal hypoxic ischemic encephalopathy: closing the gap between experimental and clinical research. Exp Neurol 2014; 261: 281-290.

3. Ten VS, Starkov A. Hypoxic-ischemic injury in the developing brain: the role of reactive oxygen species originating in mitochondria. Neurol Res Int 2012; 2012: 542976.

4. Kumral A, Yesilirmak DC, Aykan S, Genc S, Tugyan K, Cilaker S, Akhisaroglu M, Aksu I, Sutcuoglu S, Yilmaz $O$, et al. Protective effects of methylxanthines on hypoxia-induced apoptotic neurodegeneration and longterm cognitive functions in the developing rat brain. Neonatology 2010; 98(2): 128-36.

5. Rocha-Ferreira E, Sisa C, Bright S, Fautz $T$, Harris $M$, Contreras Riquelme I, Agwu C, Kurulday T, Mistry B, Hill $D$, et al. Curcumin: Novel Treatment in Neonatal Hypoxic-Ischemic Brain Injury. Front Physiol 2019; 10 : 1351.

6. Pan S, Li S, Hu Y, Zhang H, Liu Y, Jiang H, Fang M, Li Z, $X u K$, Zhang $H$, et al. Resveratrol post-treatment protects against neonatal brain injury after hypoxiaischemia. Oncotarget 2016; 7(48): 79247-79261.

7. Tu X, Wang M, Liu Y, Zhao W, Ren X, Li Y, Liu H, Gu Z, Jia $H$, Liu J, et al. Pretreatment of Grape Seed Proanthocyanidin Extract Exerts Neuroprotective Effect in Murine Model of Neonatal Hypoxic-ischemic Brain Injury by Its Antiapoptotic Property. Cell Mol Neurobiol 2019; 39(7): 953-966.

8. Nabavi SF, Braidy N, Gortzi O, Sobarzo-Sanchez E, Daglia M, Skalicka-Woźniak K, Nabavi SM. Luteolin as an anti-inflammatory and neuroprotective agent: $A$ brief review. Brain Res Bull 2015; 119(Pt A):1-11.

Trop J Pharm Res, April 2021; 20(4): 754 
9. Imran $M$, Rauf $A$, Abu-Izneid $T$, Nadeem $M$, Shariati MA, Khan IA, Imran A, Orhan IE, Rizwan M, Atif M, Gondal $T A$, et al. Luteolin, a flavonoid, as an anticancer agent: A review. Biomed Pharmacother 2019; 112: 108612.

10. National Research Council (US) Committee for the Update of the Guide for the Care and Use of Laboratory Animals. Guide for the Care and Use of Laboratory Animals. 8th ed. Washington (DC): National Academies Press (US); 2011

11. Vannucci SJ, Hagberg H. Hypoxia-ischemia in the immature brain. Exp Biol 2004; 207: 3149-54.

12. Wang L, Ke J, Li Y, Ma Q, Dasgupta C, Huang X, Zhang $L$, Xiao $D$. Inhibition of miRNA-210 reverses nicotineinduced brain hypoxic-ischemic injury in neonatal rats. Int J Biol Sci 2017; 13(1): 76-84.

13. Rodrigues Siqueira I, Fochesatto C, da Silva Torres IL, Dalmaz C, Alexandre Netto C. Aging affects oxidative state in hippocampus, hypothalamus and adrenal glands of Wistar rats. Life Sci 2005; 78(3): 271-278.

14. Ashokkumar $P$, Sudhandiran $G$. Protective role of luteolin on the status of lipid peroxidation and antioxidant defense against azoxymethane-induced experimental colon carcinogenesis. Biomed Pharmacother 2008; 62(9): 590-597.

15. Maciel EN, Vercesi AE, Castilho RF. Oxidative stress in $\mathrm{Ca}(2+)$-induced membrane permeability transition in brain mitochondria. J Neurochem 2001; 79(6): 12371245.

16. Pandurangan AK, Kumar SA, Dharmalingam $P$, Ganapasam S. Luteolin, a bioflavonoid inhibits azoxymethane-induced colon carcinogenesis:
Involvement of iNOS and COX-2. Pharmacogn Mag 2014;10(2): S306-S310.

17. Kotanidou A, Xagorari A, Bagli E, Kitsanta $P$, Fotsis $T$, Papapetropoulos A, Roussos C. Luteolin reduces lipopolysaccharide-induced lethal toxicity and expression of proinflammatory molecules in mice. Am J Respir Crit Care Med 2002; 165(6): 818-23.

18. Lin CW, Wu MJ, Liu IY, Su JD, Yen JH. Neurotrophic and cytoprotective action of luteolin in PC12 cells through ERK-dependent induction of Nrf2-driven HO-1 expression. J Agric Food Chem 2010; 58(7): 4477-4486.

19. Arteaga $O$, Alvarez A, Revuelta M, Santaolalla $F$, Urtasun A, Hilario E. Role of Antioxidants in Neonatal HypoxicIschemic Brain Injury: New Therapeutic Approaches. Int J Mol Sci 2017; 18(2): 265.

20. Gao Y, Fu R, Wang J, Yang $X$, Wen L, Feng J. Resveratrol mitigates the oxidative stress mediated by hypoxic-ischemic brain injury in neonatal rats via Nrf2/HO-1 pathway. Pharm Biol 2018; 56(1): 440-449.

21. Muralidharan $P$, Balamurugan $G$, Babu V. Cerebroprotective effect of Glycyrrhiza glabra Linn. root extract. Bangladesh J Pharmacol 2008; 4: 60-64.

22. Xu J, Wang H, Ding K, Zhang L, Wang C, Li T, Wei W, Lu $X$. Luteolin provides neuroprotection in models of traumatic brain injury via the Nrf2-ARE pathway. Free Radic Biol Med 2014; 71: 186-95.

23. Rodrigo J, Fernández AP, Serrano J, Peinado MA, Martínez $A$. The role of free radicals in cerebral hypoxia and ischemia. Free Radic Biol Med 2005; 39(1): 26-50.

24. Thornton C, Leaw B, Mallard C, Nair S, Jinnai M, Hagberg $H$. Cell Death in the Developing Brain after Hypoxia-Ischemia. Front Cell Neurosci 2017; 11: 248. 